\section{O PAPEL DO CONGRESSO NACIONAL E DO TRIBUNAL DE CONTAS DA UNIÃO NA FISCALIZAÇÃO DAS AGÊNCIAS REGULADORAS: ABDICAÇÃO OU DELEGAÇÃO DE PODERES?}

\author{
Monique Menezes
}

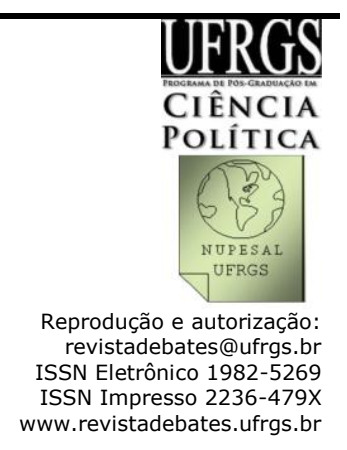

\begin{abstract}
Resumo
Este artigo analisa a accountability das instituições regulatórias brasileiras, especificamente, no controle exercido pelo Congresso Nacional brasileiro, através do Tribunal de Contas da União. A literatura brasileira tem argumentado que o controle das agências reguladoras ocorre quase que, exclusivamente, através do poder Executivo, pois este possui mecanismos institucionais mais diretos. Argumenta-se também que o Congresso Nacional teria abdicado da função de controle dessas instituições. Neste artigo, argumento que o Legislativo delega seu poder de controle sobre as agências reguladoras ao Tribunal de Contas da União (TCU). A transferência de autoridade para o controle sobre as agências reguladoras, segundo os argumentos da teoria de delegação não representaria uma abdicação do Legislativo em fiscalizar e controlar os entes autônomos, mas sim uma delegação. Para isto, apresento o resultado da pesquisa realizada a partir da análise de conteúdo dos acórdãos do TCU, resultantes das auditorias sobre as atividades fins das agências reguladoras.
\end{abstract}

Palavras-chave: Accountability Horizontal; Agências Reguladoras; Democracia.

\begin{abstract}
This article analyses the accountability of Brazilian regulatory agencies, specifically, in the control performed by the Brazilian Congress, through "Tribunal de Contas da União". Brazilian literature argues that the regulatory agencies control occurs almost, exclusively, through Executive power, since it possesses more direct institutional control mechanisms. It is also argued that the National Congress would have abdicated this control function from these institutions. In this article, I argue that the Legislative power delegates its power to control regulatory agencies to the "Tribunal de Contas da União" (TCU). This authority transfer of control over regulatory agencies, according to the theory of delegation, would not represent an abdication of the legislative power to supervise and control the agencies, but only a process about the delegation of power. The results of a research conducted with the judgments made by TCU are discussed. Those judgments are the result of auditory activities of regulatory agencies.
\end{abstract}

Keywords: Horizontal Accountability; Regulatory Agencies; Democracy. 


\section{Introdução}

A reforma do Estado brasileiro durante a década de 1990 introduziu um novo ator no arranjo institucional brasileiro: agências reguladoras dotadas de certo grau de autonomia para regularem as regras dos setores privatizados $^{1}$. Embora sejam entes autônomos, o controle e a prestação de contas dessas instituições, seja por parte dos cidadãos, dos políticos eleitos e das agências de controle horizontal, torna-se fundamental para a qualidade da democracia brasileira. A literatura tem definido as agências como organizações públicas com poderes regulatórios autônomos, mas que não são eleitas (THATCHER e STONE SWEET, 2002; GILARDI, 2008). Apesar da autonomia formal em relação aos políticos, é possível argumentar que o controle pode ser exercido através de mecanismos formais e informais.

As análises deste artigo são centradas na accountability das instituições regulatórias brasileiras, mais especificamente, no controle exercido pelo Congresso Nacional brasileiro, através do Tribunal de Contas da União. De um modo geral, a literatura brasileira tem argumentado que o controle das agências reguladoras ocorre quase que, exclusivamente, através do poder Executivo, uma vez que este possui mecanismos institucionais mais diretos como, por exemplo, o controle orçamentário e a iniciativa para nomeação dos diretores (SALGADO, 2003). Por outro lado, o Congresso Nacional teria abdicado da função de controle dessas instituições, na medida em que raras vezes os diretores dessas agências foram convocados pelas Comissões Parlamentares ou foram alvo de investigação direta pelo Congresso Nacional (BOSCHI e LIMA, 2002).

Deve-se destacar que a delegação de autoridade às agências reguladoras é igualmente concedida pelo poder Executivo e Legislativo, tendo em vista o desenho institucional de separação de poderes do país. Neste sentido, cabe questionar: O Congresso abdicou do seu poder de controle, deixando esta tarefa somente para o poder Executivo? Ou há outras formas de controle ainda não investigadas pela literatura?

Neste artigo, argumento que o Legislativo delega seu poder de controle sobre as agências reguladoras ao Tribunal de Contas da União (TCU). A transferência de autoridade para o controle sobre as agências reguladoras, segundo os argumentos da teoria de delegação não representaria uma abdicação do Legislativo em fiscalizar e controlar os entes autônomos, mas sim uma delegação. Deve-se ressaltar que o TCU é um órgão auxiliar do Congresso Nacional, que possui poderes quase-judiciais, podendo determinar ou recomendar o embargo de obras ou de decisões regulatórias consideradas ilegais.

\footnotetext{
1 Este argumento é aplicado somente à primeira geração de agências reguladoras, criadas durando o primeiro mandato do Presidente Fernando Henrique Cardoso. Para maiores detalhes sobre este tema ver Pó e Abrúcio (2006) e Menezes (2010).
} 
O artigo está dividido em quatro (4) seções, além desta introdução e de uma conclusão. Na primeira seção realizo a discussão sobre as motivações para a delegação de poderes às agências reguladoras. Em seguida, na segunda seção, apresento os problemas democráticos inerentes à delegação de poderes para burocracia. Para, na terceira seção discutir mais especificamente os mecanismos de accountability das agências reguladoras. Finalmente, na quarta seção apresento os resultados da pesquisa empírica realizada a partir da análise de conteúdo dos acórdãos do TCU, resultantes das auditorias sobre as atividades fins ${ }^{2}$ das agências reguladoras.

\section{Motivações para delegação de poderes às agências reguladoras}

A motivação dos políticos eleitos para delegarem poderes às agências reguladoras, dotadas de autonomia, é um dos temas mais pesquisado pela literatura contemporânea sobre regulação. É importante destacar que, apesar da ampla proliferação de instituições reguladoras autônomas por diversos países nas últimas décadas, este arcabouço regulatório não é, de longe, a única opção disponível para os governantes. Na América Latina e na Europa predominou, até o início dos anos 1990, a provisão de bens e serviços públicos diretamente pelo Estado, quando não havia a separação entre a prestação do serviço de utilidade pública e sua regulação. No entanto, a partir deste período observou-se um movimento em direção à regulação via agências autônomas dos Ministérios, o que acarreta na separação entre o fornecimento do serviço e a emissão de regras e normas setoriais.

O principal argumento oferecido pela literatura para a criação dessas instituições é a necessidade dos países em reduzirem as incertezas regulatórias, por meio da delegação de autoridade às burocracias autônomas do poder político. A teoria econômica argui que a decisão de investir será ótima sempre que o valor presente do investimento for positivo e o retorno do investimento não for condicionado por fatores que variam no tempo (GILARDI, 2008). Contudo, esta regra não se aplica aos setores de infraestrutura que se caracterizam pela necessidade de um longo prazo para maturação dos investimentos e pela irreversibilidade dos mesmos. Devido à primeira característica, as condições econômicas e as regras regulatórias podem sofrer alterações significativas até o período de remuneração do montante investido. Por esta razão, a delegação de poderes às agências autônomas apresentaria como objetivo diminuir os efeitos das incertezas relacionadas à política regulatória criando, assim, compromissos críveis do Estado com as empresas privadas.

No que se refere à literatura de Ciência Política, não há consenso acerca das motivações para a delegação de poderes às agências reguladoras

\footnotetext{
2 Refere-se à fiscalização dos métodos adotados pela agência para o cumprimento do seu mandato na regulação dos setores de infraestrutura, envolvendo análise de eficiência, de economicidade e de legalidade dos seus atos.
} 
autônomas. Thatcher e Stone Sweet (2003) apontam que a delegação de poderes apresenta vários resultados positivos para os políticos eleitos: fatores cognitivos, redução de custos políticos, evitar a realização direta de medidas impopulares, aumento da credibilidade regulatória e redução das incertezas políticas.

De acordo com Majone (1999) e Wilks e Bartle (2002), os defensores do argumento de que fatores cognitivos motivam a delegação de poderes às agências reguladoras sugerem que a elaboração de políticas púbicas deve ser conduzida por especialistas, que possam se adaptar às mudanças inesperadas. Neste caso, as agências autônomas, compostas por quadros técnicos especializados, teriam a capacidade de realizar políticas mais eficazes do que os políticos eleitos. Entretanto, a falha deste argumento consiste em que diversas áreas de política típicas de Estado que necessitam de especialistas, como a criação de impostos e a elaboração do orçamento, são conduzidas de forma eficaz pelos políticos eleitos. O Legislativo e o Executivo, na maioria dos países, contam com consultores altamente especializados para a formulação e avaliação da execução dessas políticas.

A delegação de responsabilidades dos políticos à burocracia também é apresentada pela literatura como uma forma de reduzir os custos políticos. Como destacado por Majone (2000), os recursos dos políticos são finitos, as dificuldades para se chegar a um acordo para a implementação de uma política pública podem acarretar em uma certa "paralisia" política, impedindo o parlamento e o Executivo de realizarem outras ações importantes para o país. Neste sentido, a regulação via agências autônomas ajudaria a resolver impasses políticos, já que o ente regulador possui autonomia para normatizar a política do setor. A agência reguladora seria um instrumento para a redução dos custos de transação dentro do Estado. Além disso, há um custo político de popularidade para os políticos na execução de medidas que vão contra os interesses imediatos dos eleitores, como aumentos de tarifa. Desta forma, a agência cumpriria também o papel de insular os danos políticos de medidas tecnicamente justificáveis, mas, impopulares.

De acordo com Majone (2000), os argumentos de redução do custo de transação político e de popularidade não são suficientes para elucidar a adesão de diversos países ao modelo de regulação autônoma, a partir da década de 1990. O autor retoma o argumento econômico afirmando que a principal explicação para a delegação de poderes às instituições autônomas consiste na necessidade dos Estados em criar compromissos críveis. Wilks e Bartle (2002) também argumentam nesta direção. Segundo os autores, é preciso isolar a administração pública dos interesses dos partidos políticos para que sejam elaboradas regras estáveis para os regulados e para os consumidores em geral. A criação de regras claras permite que os governos consigam captar recursos para os setores de infraestrutura, que necessitam de investimentos de longo prazo, principal objetivo das privatizações. 
As correntes da literatura não conseguem explicar, isoladamente, a delegação de poderes às agências reguladoras. Por esta razão, muitos autores focados neste tema procuram combinar seus principais argumentos para a elaboração de um modelo analítico mais abrangente. No Brasil pode-se argumentar que a delegação de poderes às primeiras agências reguladoras ocorreu com o objetivo de aumentar a credibilidade de setores que seriam privatizados na década de 1990 . Entretanto, esta mudança, da regulação direta pelos políticos eleitos para a delegação a entes autônomos, foi mediada por arranjos institucionais anteriores. Isto explica, por exemplo, as diferenças institucionais existentes entre as agências reguladoras federais, cada uma delas apresenta características que estão relacionadas, em alguma medida, à trajetória específica do setor. Deste modo, percebe-se que não há uma única explicação causal para a alteração do desenho institucional regulatório, ao contrário, um conjunto de fatores determinou a mudança da arena regulatória em diversos países, inclusive no Brasil.

\section{Problemas de delegação às agências reguladoras}

A relação entre os políticos eleitos e a burocracia especializada a quem os primeiros delegam poderes para a implementação de políticas públicas é um tema em aberto na teoria política. A longa tradição do sistema político norte-americano de delegar autoridade às agências reguladoras resultou em um amplo debate acadêmico neste país, com a produção de uma vasta literatura sobre a relação entre os políticos eleitos e a burocracia.

Os autores americanos argumentam na direção de que em democracias modernas representativas a delegação de poderes é inevitável (KIEWIET e MCCUBBINS, 1991; PRZEWORSKI, 2003). Os eleitores, através das eleições, delegam autoridade aos seus representantes. No caso de regimes presidencialistas, a representação ocorre por meio de dois poderes independentes: o Legislativo e o Executivo. A rede de delegação continua: o presidente delega poderes aos seus ministros e à burocracia, ao mesmo tempo, o Congresso incumbe, internamente, funções às suas comissões especializadas e aos líderes partidários e, externamente, à burocracia.

Neste contexto, de delegação do sistema político, a execução da política pública é realizada através da ação coletiva dentro de cada poder e entre eles (KIEWIET e MCCUBBINS, 1991). O Congresso precisa se organizar para o aperfeiçoamento da legislação e supervisionar a burocracia, a quem ele delega poderes. O Executivo, para implementar sua política de governo, deve coordenar seus ministros junto à burocracia, que também é subordinada aos membros do Congresso Nacional. Por fim, ambos, o Executivo e o Congresso devem considerar o Judiciário em suas ações, quando este último possui papel revisor, cujo objetivo normativo é prevenir abusos do poder público, sejam eles praticados pelos políticos eleitos ou pela burocracia (PRZEWORSKI, 2003). 
O processo de delegação aqui descrito representa um complexo de relações hierárquicas. Para um melhor entendimento dessas relações a ciência política utiliza a "teoria da agência" ou "principal-agentmodel" ${ }^{3}$, desenvolvida a partir da análise organizacional de empresas privadas. Este modelo de análise possui o objetivo de esclarecer problemas de controle hierárquico, quando há conflito de interesses e assimetria de informações (MOE, 1984).

De acordo com Kiewiet e McCubbins (1991), a delegação de poderes por um indivíduo ou instituição (mandante), que foi originalmente incumbido de uma tarefa, para um outro sujeito (mandatário) caracteriza a relação mandante-mandatário. Em termos gerais, o modelo de delegação requer no mínimo dois atores: o mandante e o mandatário. O mandatário é sempre o primeiro a agir, propondo uma alternativa ao status quo. Em seguida, o mandante possui a opção de aceitar a proposta ou de rejeitá-la em favor do status quo. A interação básica entre o mandante e o agente mandatário pode ser observada na figura, a seguir:

Figura 1 - Modelo básico de delegação

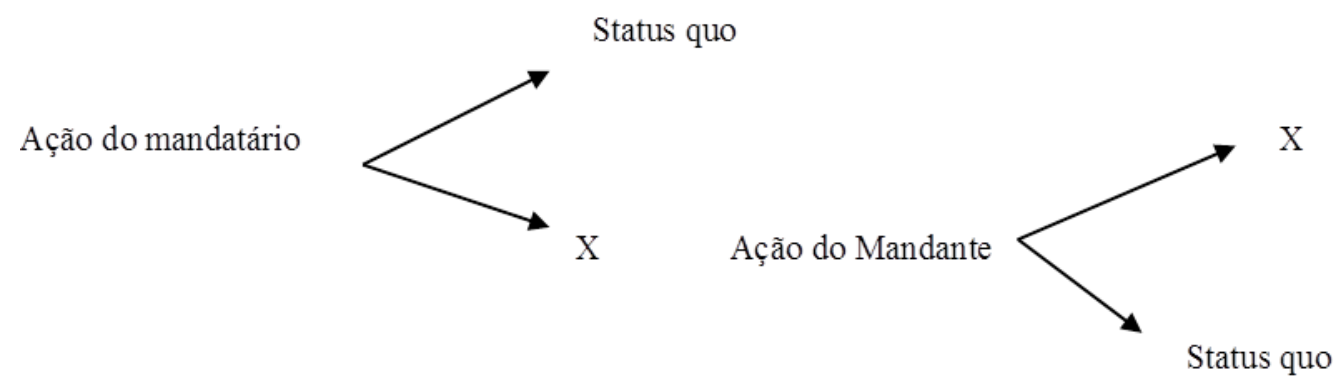

Fonte: Adaptado de Lupia e McCubbins (1998).

O problema de delegação, como apontado por Lupia e McCubbins (1998), refere-se à assimetria de informação e ao conflito de interesses entre o mandante e o mandatário. Em geral, dada a sua natureza política e não técnica, o mandante carece de informações precisas para avaliar se as ações do mandatário estão ou não de acordo com os seus interesses. Por possuir informações privilegiadas, que não estão disponíveis ao mandante, o mandatário pode realizar ações de seu interesse, em detrimento do interesse do mandante. Dessa forma, esta se constitui uma relação, naturalmente, conflituosa, gerando dois tipos de problemas denominados pela literatura de "perdas de agência" (agencylosses).

\footnotetext{
${ }^{3}$ Neste artigo, a expressão principal-agent será traduzida como mandante-mandatário. De acordo com o Dicionário Aurélio Século XXI (FERREIRA, 2009), o mandante é a pessoa que outorga um mandato a outrem, chamado, desta forma, mandatário.
} 
Primeiro, o mandatário pode, sistematicamente, optar por ações que sejam contrárias aos desejos do mandante. Segundo, para garantir o cumprimento de seus interesses, o mandante precisa criar mecanismos de controle que demandam recursos significativos. Neste último caso, o custo para monitorar as ações do mandatário pode se tornar elevado demais, ao ponto da delegação de poderes deixar de ser eficiente para o mandante. Lupia e McCubbins (1998) argumentam que, na ausência de mecanismos de controle, a delegação torna-se uma abdicação do poder. Assim, a delegação é bem sucedida, ou seja, não gera abdicação, somente quando as ações do mandatário aumentar as condições de bem-estar do mandante. Por conseguinte, a delegação falha quando as ações do mandatário são contrárias ao interesse do mandante.

As informações assimétricas e os conflitos de interesses tornam-se mais crônicos quando há situações de múltiplos mandantes e múltiplos mandatários, como é o caso específico da delegação política que envolve a burocracia, o Congresso, o Executivo e os eleitores. Além disso, quando há múltiplos mandatários, podem ocorrer situações de conluio contra os mandantes, devido à especialização da burocracia (MOE 1984; WEINGAST 2006).

Alguns autores norte-americanos que estudam a relação entre o Congresso e a burocracia deste país, como Lowi (1979), argumentam que a delegação de autoridade para agências regulatórias resulta, sempre, em uma abdicação dos políticos eleitos das suas responsabilidades. De acordo com o autor, inicialmente, a delegação para as comissões regulatórias norteamericanas era mais limitada e definida, não sendo caracterizada por abdicação. No entanto, progressivamente, o Congresso americano delegou mais atividades de elaboração das políticas públicas às agências reguladoras, aumentando o poder discricionário dessas instituições no sistema político do país. Desta forma, a falha desta ampla delegação consiste no fato de que o Congresso não possui capacidade de controle sobre esta burocracia.

Embora, em teoria, os políticos eleitos possam inserir mecanismos de accountability no sistema de delegação, tendo em vista que são os responsáveis pelas regras de atuação da burocracia, Fisher (1981) afirma que a natureza dos mecanismos de delegação impede uma ampla supervisão dos políticos acerca da elaboração ${ }^{4}$ e da implementação das políticas públicas.

Apesar das críticas elaboradas por parte da literatura americana, Lupia e McCubbins (1998) sustentam que, sob certas condições específicas, a delegação de poderes dos políticos eleitos à burocracia pode ser bem sucedida. Para os autores, a crítica da literatura de que a delegação de poderes para a burocracia sempre resulta em falhas não considera a possibilidade de aprendizado e adaptação do mandante ao problema de limitação de informações. De acordo com os autores, as perdas geradas pela

\footnotetext{
${ }^{4}$ Em alguns casos, a legislação de um setor é muito geral, permitindo que a agência tome a iniciativa para a elaboração da política pública.
} 
assimetria de informação podem ser superadas, possibilitando que as ações da burocracia sejam alinhadas aos interesses dos políticos eleitos e, consequentemente, dos eleitores ${ }^{5}$. Este tema será detalhado na próxima seção com a discussão sobre a accountability das agências reguladoras.

\section{A accountability do regime regulatório}

O modelo de agência reguladora autônoma tem suscitado a discussão dos riscos que esse desenho institucional representa para a democracia representativa. Segundo Diniz (1998), a centralização decisória em burocracias insuladas do controle político enfraquece os suportes institucionais democráticos, ou seja, o controle mútuo entre os três poderes, e o controle social, do público em geral sobre as atividades do Estado.

O pressuposto ideológico deste desenho institucional consiste em que os critérios de eficácia, eficiência e de adequação técnica devem se sobrepor às decisões políticas, de justiça relativa entre grupos da sociedade, por exemplo, de forma a proporcionar um ambiente de mercado favorável aos investimentos. Daí a necessidade de reformar o arcabouço regulatório prévio e conferir autonomia ante os políticos eleitos às instituições reguladoras. Deste ponto de vista, a accountability e os mecanismos de transparência e controle são centrais para uma atuação legítima dessas instituições. Sem uma definição clara desses mecanismos, a delegação de autoridade perde seu sentido na medida em que pode ocorrer um comportamento oportunista por parte dos dirigentes dessas agências.

No Brasil, as atividades antes exercidas diretamente pelo Executivo foram transferidas para empresas privadas e o controle dos agentes econômicos foi delegado a uma burocracia autônoma. Além da mudança na estrutura formal de deliberações, também há a inclusão de novos atores no ambiente regulatório: empresas nacionais e internacionais, usuários dos serviços de utilidade pública, investidores, entre outros. Como esses atores possuem interesses conflitantes, também se faz necessária a elaboração de mecanismos de transparência do processo de tomada de decisões e de sistemas de ampla prestação de contas dos reguladores. Estes dispositivos proporcionam uma arena regulatória confiável e previsível, tanto do ponto de vista do usuário quanto do investidor. Essas modificações da governança regulatória demandam um reordenamento dos antigos instrumentos de accountability, com inovações institucionais que necessariamente variam entre os países, de acordo com as trajetórias específicas do sistema político e da cultura nacional.

\footnotetext{
${ }^{5}$ É importante ressaltar que esta relação direta entre a vontade dos políticos e dos eleitores é mais direta quando há uma forte conexão eleitoral. A literatura argumenta que sistemas centrados nos candidatos e a competição intrapartidária enfraquecem esta conexão e, consequentemente, a accountability. Para uma discussão mais ampla deste tema ver Moreno, Chrisp e Shugart (2003).
} 
A questão teórica mais central desta literatura retoma o debate weberiano sobre os desafios decorrentes da delegação de poderes por políticos eleitos a experts (MELO, 2001). Em termos empíricos, a reforma regulatória levanta as questões que se seguem:

1. Como fornecer autonomia às agências e ao mesmo tempo controlar suas atividades?

2. Como operacionalizar efetivamente os mecanismos de accountability e transparência (LODGE, 2004)? 2004)?

3. Para quem a agência reguladora deve ser accountable (LODGE,

\section{Definindo Accontability}

De um modo geral, a accountability pode ser definida como normas e regras de prestação de contas que um ator institucional ou político deve prestar a sociedade ou a outra instituição. Seu objetivo é sempre o de aumentar a transparência decisória, de modo a elevar a qualidade da democracia.

Guilhermo O'Donnell (1994) classifica e qualifica accountability em dois níveis: horizontal e vertical. Esta última refere-se às ações realizadas, por grupos ou indivíduos, que afetam aqueles que ocupam posições em instituições do Estado, sejam eles eleitos ou não. Nesta definição, as eleições constituem um importante mecanismo de accountability vertical, onde os cidadãos podem reeleger ou destituir os políticos. A segunda definição apresentada pelo autor, accountability horizontal, consiste na existência de agências estatais que possuem o direito e o poder legal para a realização de ações de supervisão de rotina e a imputação de sanções legais sobre outras agências do Estado. Neste caso, as instituições de supervisão possuem poder de controle sobre as demais, com a possibilidade de impor sanções legais.

Neste artigo estabeleço algumas diferenças essenciais do que se entende pelos conceitos de accountability vertical e horizontal sobre as agências reguladoras. A partir da definição geral de accountability horizontal, apresentada por O'Donnell (1994), uma agência reguladora será considerada accountable a outra instituição, quando esta for capaz de impor sobre aquela suas demandas, seja por incentivos, seja por restrições e penalidades. Por outro lado, o conceito de accountability vertical inclui a existência de mecanismos que permitam a participação dos cidadãos na definição e na avaliação das decisões das agências. Para que isto se torne possível, é imprescindível a existência de instituições que possibilitem ao cidadão contestar as ações do poder público - políticos eleitos, agências reguladoras e a burocracia em geral -, bem como, a disponibilidade das informações acerca dessas ações, ou seja, a transparência do processo decisório. 
Para a análise da accountability na arena regulatória, a discussão também deve considerar três aspectos fundamentais: o objeto sobre o qual se exerce o controle e a accountability, quem o exerce e como. De acordo com Lodge (2004) e Scott (2000), o modelo de regulação autônoma contribuiu para o aumento da complexidade das relações dentro da arena regulatória, envolvendo distintas agências de governo, os políticos eleitos, o corpo regulatório autônomo, os consumidores de cada setor regulado, as empresas reguladas, os acionistas e a população. A elaboração de políticas em áreas tão sensíveis pode estabelecer uma relação conflitante entre a eficiência econômica e o bem-estar social.

A arena regulatória, dessa forma, apresenta mecanismos múltiplos e complexos de accountability. Entre outros, a sociedade política monitora diretamente os políticos eleitos - através de eleições regulares -, estes por sua vez monitoram as agências reguladoras, responsáveis pela regulação dos agentes econômicos. Os cidadãos-usuários de cada setor regulado sofrem os efeitos das ações das empresas e pleiteiam ação do ente regulador, dos políticos e do Judiciário. Grupos de interesse sociais e econômicos atuam sobre a agência reguladora, procurando influenciar na definição regulatória. 0 Legislativo, o Judiciário e o Executivo, por sua vez, atuam uns sobre os outros, exercendo um controle mútuo fundamental na democracia. A figura a seguir resume esta interação. 
DOSSIÊ GOVERNABILIDADE, INFORMAÇÃO E FISCALIZAÇÃO POLÍTICA

Figura 2 - Rede de Controle sobre as agências reguladoras

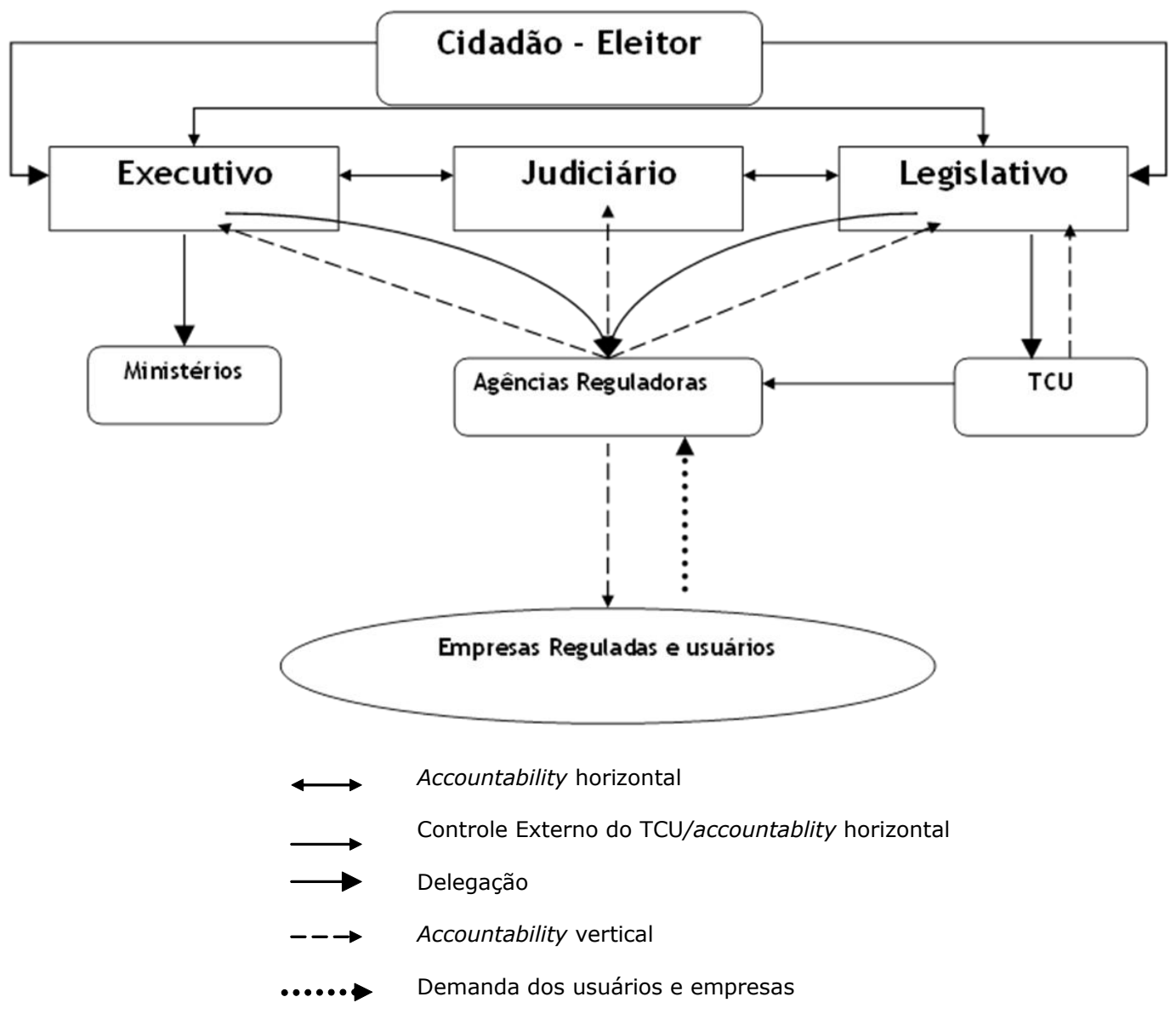

Fonte: Elaboração própria.

\section{Formas de controle político das agências reguladoras}

A literatura apresenta duas formas de controle dos políticos eleitos sobre as agências reguladoras: o controle ex ante e ex post. 0 primeiro refere-se às limitações inseridas no desenho institucional da própria burocracia que se pretende controlar. Já o segundo são mecanismos de controle desenhados para que os políticos eleitos reajam após a tomada de decisão das agências reguladoras. As análises deste artigo concentram-se no controle ex post.

De acordo com Przeworski (2003), toda democracia representativa pode ser estruturada de tal forma que as burocracias responsáveis pela tomada de decisões sejam adversárias dentro do governo, gerando uma 


\section{DOSSIÊ GOVERNABILIDADE, INFORMAÇÃO E FISCALIZAÇÃO POLÍTICA}

interação entre múltiplos mandatários com objetivos distintos. Assim, a construção da rede de delegação pode contar com mecanismos institucionais de accountability horizontal, de forma que a delegação de poderes a um mandatário possua, no mínimo, outro mandatário com autoridade para vetar ou bloquear as ações do primeiro, caso isto seja necessário (PRZEWORSKI 2003; KIEWIET e MCCUBBINS, 1991).

Este tipo de controle pode ser realizado por dois caminhos. Primeiro, entre os poderes, o Legislativo supervisiona as ações da burocracia vinculada diretamente ao Executivo e vice-versa. Segundo, pela própria burocracia do Estado, distintos órgãos podem receber poder de sanção sobre outros. Para este último caso, o controle institucional só é desejável quando os mandatários possuem incentivos para serem conflitivos, caso contrário, podem ocorrer situações de conluio entre as burocracias. Kiewiet e McCubbins (1991) apontam que o controle institucional inibe que um mandatário realize ações indesejadas pelo mandante, mas, também, protela ações desejáveis por este. Assim, uma consequência negativa para o setor regulado pode ser a dificuldade em realizar mudanças, quando há múltiplos agentes com poder de veto.

O controle dos políticos, também, pode ser realizado através de supervisão direta das atividades das agências, através de relatórios anuais e auditorias. Esse tipo de controle é caracterizado pelo monitoramento constante da burocracia pelo Congresso e pelo Executivo. Em geral, o parlamento de qualquer país pode realizar auditorias investigativas sobre as agências reguladoras. Na Inglaterra, por exemplo, o National Audit Office (NAO), órgão equivalente ao TCU brasileiro, auxilia o parlamento inglês na fiscalização de todos os órgãos públicos, inclusive as agências reguladoras (BOURN, 2005) ${ }^{6}$.

Segundo Weingast (2006), os políticos eleitos preferem controlar a burocracia utilizando mecanismos que minimizem esforços, tempo e recursos, para se dedicarem ao seu mandato político específico. Para Kiewiet e McCubbins (1991), como o Congresso recebe todos os anos milhares de relatório das burocracias, apresentando as atividades de audiências e consultas públicas, investigações e recomendações, o consumo de toda essa informação demanda muito recurso pessoal da elite política. Os parlamentares precisariam ler, detalhadamente, relatórios sobre temas que eles não possuem domínio técnico para julgar o teor das informações. Além disso, como são relatórios produzidos pelas próprias agências reguladoras, o conteúdo das informações não é totalmente confiável, na medida em que nenhuma burocracia apontaria seus pontos fracos.

No caso específico da política regulatória, este problema ocorre, sobretudo, na relação entre o Congresso Nacional e as agências. O poder

\footnotetext{
${ }^{6} \mathrm{O}$ controle político também pode ocorrer através da restrição orçamentária da burocracia e da mudança do seu mandato institucional. Como este artigo enfatiza o controle horizontal realizado por outras instituições de Estado, a discussão destas formas de controle não será realizada.
} 
Executivo, em geral, possui técnicos especialistas lotados em seus ministérios que podem contestar as ações das agências mais facilmente.

A partir dessas críticas ao controle conhecido como "patrulha policial" (policepatrol) das agências reguladoras e da burocracia como um todo, McCubbins e Schwartz (1984) argumentam que o controle efetivo ocorre apenas quando há o "elemento surpresa". Neste caso, em vez de examinar centenas de relatórios, o mandante pode acionar uma terceira parte, com o objetivo de fazê-la funcionar como um "alarme de incêndio" (firealarm). Como terceira parte, entende-se aqui a imprensa, as empresas reguladas, os usuários de um serviço e outras instituições do Estado, que possuam interesses conflitantes.

De acordo com os autores, o mecanismo de alarme de incêndio apresenta vantagens sobre as demais formas de controle. O custo para se obter as informações é menor, uma vez que o mandante não precisa despender tempo sobre centenas de relatórios. A qualidade dos dados, também, é melhor, já que o mandante ao examinar os relatórios (policepatrol) das agências pode não notar desvios importantes cometidos pelo mandatário. Enquanto, através do mecanismo de alarme de incêndio, as terceiras partes apontam problemas específicos na atuação do mandatário.

Meu argumento, neste artigo, é de que o Tribunal de Contas da União funciona para o Congresso brasileiro, tanto como um mecanismo de patrulha policial quanto de alarme de incêndio. O TCU realiza diversas auditorias sobre as atividades fins das agências reguladoras, seja por iniciativa própria ou por solicitação do Congresso e monitora o cumprimento de suas decisões. Neste caso, a Corte de Contas atua como uma patrulha policial.

Como algumas auditorias do Tribunal têm grande repercussão na mídia ou entre as agências reguladoras e as empresas reguladas, o órgão de controle externo também pode funcionar como um mecanismo de alarme de incêndio para os congressistas. Os políticos podem dedicar maior atenção às auditorias de temas que sejam considerados mais importantes para a sociedade como, por exemplo, o aumento de tarifas.

Com o objetivo de confirmar este argumento, a próxima seção analisa o mandato institucional do TCU, verificando em que medida a instituição possui mecanismos para atuar, simultaneamente, como ente de controle policial e de alarme de incêndio.

\section{Fiscalização do Tribunal de Contas da União sobre as atividades fins das agências reguladoras}

Atualmente, o Brasil conta com dez agências reguladoras autônomas federais, nos setores de energia elétrica, telecomunicações, petróleo, saúde suplementar, saúde sanitária, água, cinema, transporte terrestre, aquaviário e aéreo. Dentre essas agências, nove foram criadas durante o primeiro e o segundo mandato do ex-presidente Fernando Henrique Cardoso e a de 
aviação civil durante o primeiro mandato do ex-presidente Luiz Inácio Lula da Silva.

As análises empíricas serão focadas apenas nas agências de energia, petróleo e telecomunicações, Aneel - Agência Nacional de Energia Elétrica, Anatel - Agência Nacional de Telecomunicações e ANP - Agência Nacional do Petróleo, Gás Natural e Biocombustíveis, respectivamente. A escolha destas agências justifica-se pela maior maturidade institucional, já que foram as primeiras agências criadas. $O$ estudo conta com uma análise de conteúdo dos acórdãos e de discurso de quinze (15) entrevistas em profundidade realizadas com políticos e auditores do TCU.

O objeto de estudo desta seção será as auditorias realizadas pela Sefid (Secretaria de Fiscalização e Desestatização e Regulação). A Sefid é uma unidade técnica do TCU, criada após a Reforma do Estado da década de 1990, cujo principal escopo consiste em analisar os processos de privatização e fiscalizar as atividades fins das agências reguladoras autônomas dos setores de infraestrutura. A população total de acórdãos, que contém as informações sobre a atuação do TCU na arena regulatória dos setores de energia, petróleo e telecomunicações é composta por 292 casos. O período de coleta de dados corresponde aos anos de 1993 e o primeiro semestre de $2009^{7}$.

\section{A atuação do Tribunal de Contas}

A partir do levantamento e seleção dos acórdãos relativos às atividades fins da regulação autônoma e da leitura de suas respectivas ementas, foi realizada uma classificação de temas por acórdãos, como mostra a tabela a seguir. Como podemos observar, há uma abrangência temática considerável, distribuída em vinte e um (21) temas distintos. O tópico mais abordado nas auditorias finalísticas sobre as agências reguladoras dos setores de petróleo, energia e telecomunicações é "concessões", com 51,37\%, seguido pelos temas de privatização e tarifas com $9,25 \%$ e $8,90 \%$, respectivamente.

\footnotetext{
7 Deve-se destacar que existem outros acórdãos de fiscalização do TCU sobre as agências reguladoras que não interessam ao tema de investigação deste artigo como, por exemplo, a fiscalização de contas e a de recursos humanos.
} 
Tabela 1 - Temas Auditados

\begin{tabular}{l|c|c}
\hline \multicolumn{1}{c|}{ Tema da Auditoria } & $\mathrm{N}$ & $\%$ \\
\hline Concessões & $\mathbf{1 5 0}$ & $\mathbf{5 1 , 3 7}$ \\
\hline Privatização & 27 & 9,25 \\
\hline Tarifas & 26 & 8,90 \\
\hline Comercialização de Energia & 15 & 5,14 \\
\hline Processo de Licitação & 12 & 4,11 \\
\hline Universalização de Serviços & 10 & 3,42 \\
\hline Fiscalização do Funcionamento do Setor & 8 & 2,74 \\
\hline Avaliação do Processo Interno da Agência & 7 & 2,40 \\
\hline Impacto Ambiental & 7 & 2,40 \\
\hline Qualidade da Prestação dos Serviços & 7 & 2,40 \\
\hline Programas Sociais & 5 & 1,71 \\
\hline Geração de Energia & 4 & 1,37 \\
\hline Crise Energética & 3 & 1,03 \\
\hline Contratação de Recursos Humanos & 2 & 0,68 \\
\hline Metas Decenais de Energia & 2 & 0,68 \\
\hline Royalteis de Petróleo e Gás Natural & 2 & 0,68 \\
\hline Contingenciamento Financeiro & 1 & 0,34 \\
\hline Distribuição de Energia & 1 & 0,34 \\
\hline Gestão de Fundos do Setor & 1 & 0,34 \\
\hline Perdas de Energia & 1 & 0,34 \\
\hline Programa de Eficiência Energética & 292 & 100 \\
\hline & & \\
\hline & & 0,34 \\
\hline
\end{tabular}

Nas auditorias finalísticas referentes às concessões dos setores regulados, o Tribunal busca avaliar o conteúdo dos contratos firmados entre as agências e as empresas reguladas. A concessão dos serviços públicos foi, de fato, o primeiro foco da Corte de Contas, devido à flexibilização dos monopólios dos serviços de telecomunicações e exploração de petróleo, bem como a entrada de novas empresas privadas no setor elétrico. A Instrução Normativa (IN) n. 10 de 22/11/1995 tratou da fiscalização das concessões, permissões e autorizações dos serviços públicos. Em 1998, a IN n. 10 foi substituída pela de n. 27, em que foram detalhados os procedimentos do Tribunal de Contas para a realização das auditorias de conteúdo.

A tabela a seguir apresenta os temas das auditorias nos setores selecionados para a pesquisa. Como pode ser verificado, há uma variação de temas de acordo com os setores estudados. Como as concessões representam mais de $50 \%$ das auditorias sobre as atividades fins das agências reguladoras, o tema se mostrou presente nos três setores, com 47,56\% das auditorias de energia, 53,13\% das auditorias do setor de telecomunicações e 65,63\% para o setor de petróleo e gás. Contudo, podemos observar que, além das 
concessões, 15,24\% dos acórdãos do setor de energia elétrica são dedicados à análise de revisão tarifária. Já no setor de telecomunicações, a privatização e a universalização dos serviços públicos aparecem logo após as concessões, com $11,46 \%$ e 10,42\%, respectivamente. Na área de petróleo e gás, o percentual de auditorias relacionadas à concessão é maior devido às suas características: é um setor que, na distribuição, sempre foi privado e as tarifas dos produtos derivados de petróleo são, atualmente, controladas diretamente pelo governo federal.

Tabela 2 - Setor Auditado por Tema

\begin{tabular}{|c|c|c|c|c|c|}
\hline Temas & & $\begin{array}{l}\text { Energia } \\
\text { Elétrica }\end{array}$ & $\begin{array}{c}\text { Petróleo } \\
\text { e Gás }\end{array}$ & Telecom & Total \\
\hline \multirow{2}{*}{ Avaliação do Processo Interno da Agência } & $\mathrm{N}$ & 1 & 4 & 2 & 7 \\
\hline & $\%$ & 0,61 & 12,50 & 2,08 & 2,40 \\
\hline \multirow{2}{*}{ Comercialização de Energia } & $\mathrm{N}$ & 15 & 0 & 0 & 15 \\
\hline & $\%$ & 9,15 & 0 & 0 & 5,14 \\
\hline \multirow{2}{*}{ Concessões } & $\mathrm{N}$ & 78 & 21 & 51 & 150 \\
\hline & $\%$ & 47,56 & 65,63 & 53,13 & 51,37 \\
\hline \multirow{2}{*}{ Fiscalização do Funcionamento do Setor } & $\mathrm{N}$ & 5 & 1 & 2 & 8 \\
\hline & $\%$ & 3,05 & 3,13 & 2,08 & 2,74 \\
\hline \multirow{2}{*}{ Geração de Energia } & $\mathrm{N}$ & 4 & 0 & 0 & 4 \\
\hline & $\%$ & 2,44 & 0 & 0,00 & 1,37 \\
\hline \multirow{2}{*}{ Impacto Ambiental } & $\mathrm{N}$ & 4 & 3 & 0 & 7 \\
\hline & $\%$ & 2,44 & 9,38 & 0 & 2,40 \\
\hline \multirow{2}{*}{ Outro } & $\mathrm{N}$ & 10 & 2 & 2 & 14 \\
\hline & $\%$ & 6,10 & 6,25 & 2,08 & 4,79 \\
\hline \multirow{2}{*}{ Privatização } & $\mathrm{N}$ & 15 & 1 & 11 & 27 \\
\hline & $\%$ & 9,15 & 3,13 & 11,46 & 9,25 \\
\hline \multirow{2}{*}{ Processo de Licitação } & $\mathrm{N}$ & 1 & 0 & 11 & 12 \\
\hline & $\%$ & 0,61 & 0 & 11,46 & 4,11 \\
\hline \multirow{2}{*}{ Programas Sociais } & $\mathrm{N}$ & 5 & 0 & 0 & 5 \\
\hline & $\%$ & 3,05 & 0 & 0 & 1,71 \\
\hline \multirow{2}{*}{ Qualidade da Prestação dos Serviços } & $\mathrm{N}$ & 1 & 0 & 6 & 7 \\
\hline & $\%$ & 0,61 & $\mathbf{0}$ & 6,25 & 2,40 \\
\hline \multirow{2}{*}{ Tarifas } & $\mathrm{N}$ & 25 & 0 & 1 & 26 \\
\hline & $\%$ & 15,24 & 0 & 1,04 & 8,90 \\
\hline \multirow{2}{*}{ Universalização de Serviços } & $\mathrm{N}$ & 0 & 0 & 10 & 10 \\
\hline & $\%$ & $\mathbf{0}$ & $\mathbf{0}$ & 10,42 & 3,42 \\
\hline \multirow{2}{*}{ Total } & $\mathrm{N}$ & 164 & 32 & 96 & 292 \\
\hline & $\%$ & 100 & 100 & 100 & 100 \\
\hline
\end{tabular}

Fonte: Elaboração própria. 
Entre os acórdãos coletados para este estudo, verificou-se que $11,64 \%$ das auditorias sobre as atividades fins das agências reguladoras foram de autoria do Congresso Nacional, enquanto o TCU iniciou $83,6 \%$ dos processos. Este resultado é consequência da ampla autonomia conferida à Corte de Contas no Brasil. Em outros países como, por exemplo, os Estados Unidos a iniciativa em fiscalizar as agências reguladoras deve ser realizada em conjunto pelo Goverment Accountability Office $(G A O)^{8}$ e as comissões específicas do Congresso Americano.

A tabela abaixo apresenta uma análise entre o ator institucional que iniciou a auditoria e o ator auditado. Como podemos verificar, o Tribunal de Contas da União concentra $75,92 \%$ das suas iniciativas de auditoria sobre 0 conteúdo das atividades das agências reguladoras, enquanto, o Congresso Nacional se divide entre as agências, com $44,12 \%$, e as agências e empresas do setor com $26,47 \%$.

Tabela 3 - Ator Institucional Auditado por Ator Institucional que Iniciou a Auditoria

\begin{tabular}{|c|c|c|c|c|c|c|c|}
\hline \multirow{2}{*}{$\begin{array}{c}\text { Ator que } \\
\text { Iniciou a } \\
\text { Auditoria } \\
\text { no TCU }\end{array}$} & & \multicolumn{5}{|c|}{ Ator Auditado } & \multirow[t]{2}{*}{ Total } \\
\hline & & $\begin{array}{c}\text { Agência } \\
\text { Reguladora }\end{array}$ & $\begin{array}{c}\text { Agência } \\
\text { e } \\
\text { Empresa }\end{array}$ & $\begin{array}{c}\text { Agência } \\
\text { e } \\
\text { Executivo }\end{array}$ & Empresa & Executivo & \\
\hline \multirow{2}{*}{$\begin{array}{l}\text { Congresso } \\
\text { Nacional }\end{array}$} & $\mathrm{N}$ & 15 & 9 & 0,00 & 5 & 5 & 34 \\
\hline & $\%$ & 44,12 & 26,47 & 0 & 14,71 & 14,71 & 100 \\
\hline \multirow{2}{*}{ Executivo } & $\mathrm{N}$ & 0 & 2 & 0 & 0 & 1 & 3 \\
\hline & $\%$ & 0 & 66,67 & 0 & 0 & 33,33 & 100 \\
\hline \multirow{2}{*}{ TCU } & $\mathrm{N}$ & 186 & 7 & 12 & 21 & 19 & 245 \\
\hline & $\%$ & 75,92 & 2,86 & 4,90 & 8,57 & 7,76 & 100 \\
\hline \multirow{2}{*}{ Outro } & $\mathrm{N}$ & 9 & 0 & 0 & 1 & 0 & 10 \\
\hline & $\%$ & 90 & 0 & 0 & 10 & 0 & 100 \\
\hline \multirow{2}{*}{ Total } & $\mathrm{N}$ & 210 & 18 & 12 & 27 & 25 & 292 \\
\hline & $\%$ & 71,92 & 6,16 & 4,11 & 9,25 & 8,56 & 100 \\
\hline
\end{tabular}

No que se refere às demandas de fiscalização de matérias regulatórias, foi possível observar que há uma diferença na ênfase dos temas de iniciativa do Tribunal e do Congresso. Como pode ser observado na tabela, a seguir, $58,2 \%$ das auditorias iniciadas pela Corte de Contas são referentes ao tema concessões. Por outro lado, os parlamentares apresentam padrão mais diversificado, apresentando interesse em diversas áreas da regulação, sem grande concentração em um único tema. Este resultado pode ser atribuído à natureza técnica do TCU, quando comparado aos interesses dos congressistas. Além disso, nos primeiros anos após a privatização a Corte de

\footnotetext{
${ }^{8}$ O GAO possui função semelhante ao Tribunal de Contas da União, entretanto, sua estrutura institucional segue o padrão dos países anglo-saxões com um auditor geral no topo da sua estrutura.
} 
Contas concentrou a maior parte das fiscalizações sobre o desenho dos contratos de concessão. Diversificando sua atuação somente após um amadurecimento institucional da atuação das próprias agências reguladoras.

Tabela 4 - Tema por Ator que Iniciou a Auditoria

\begin{tabular}{|c|c|c|c|c|}
\hline \multirow{2}{*}{ Tema } & & \multicolumn{2}{|c|}{$\begin{array}{c}\text { Ator que Iniciou a } \\
\text { Auditoria }\end{array}$} & \multirow{2}{*}{ Total } \\
\hline & & TCU & $\begin{array}{c}\text { Congresso } \\
\text { Nacional }\end{array}$ & \\
\hline \multirow{2}{*}{ Concessões } & $\mathrm{N}$ & 142 & 4 & 146 \\
\hline & $\%$ & 58,20 & 11,80 & 52,50 \\
\hline \multirow{2}{*}{ Privatização } & $\mathrm{N}$ & 20 & 6 & 26 \\
\hline & $\%$ & 8,20 & 17,60 & 9,40 \\
\hline \multirow{2}{*}{ Tarifas } & $\mathrm{N}$ & 25 & 1 & 26 \\
\hline & $\%$ & 10,20 & 2,90 & 9,40 \\
\hline \multirow{2}{*}{ Comercialização de Energia } & $\mathrm{N}$ & 7 & 6 & 13 \\
\hline & $\%$ & 2,90 & 17,60 & 4,70 \\
\hline \multirow{2}{*}{ Processo de Licitação } & $\mathrm{N}$ & 10 & 2 & 12 \\
\hline & $\%$ & 4,10 & 5,90 & 4,30 \\
\hline \multirow{2}{*}{ Universalização dos Serviços } & $\mathrm{N}$ & 5 & 4 & 9 \\
\hline & $\%$ & 2,00 & 11,80 & 3,20 \\
\hline \multirow{2}{*}{ Fiscalização do Funcionamento do Setor } & $\mathrm{N}$ & 4 & 2 & 6 \\
\hline & $\%$ & 1,60 & 5,90 & 2,20 \\
\hline \multirow{2}{*}{$\begin{array}{l}\text { Avaliação do Processo Interno da } \\
\text { Agência }\end{array}$} & $\mathrm{N}$ & 6 & 0 & 6 \\
\hline & $\%$ & 2,50 & 0 & 2,20 \\
\hline \multirow{2}{*}{ Impacto Ambiental } & $\mathrm{N}$ & 6 & 1 & 7 \\
\hline & $\%$ & 2,50 & 2,90 & 2,50 \\
\hline \multirow{2}{*}{ Qualidade da Prestação dos Serviços } & $\mathrm{N}$ & 3 & 4 & 7 \\
\hline & $\%$ & 1,20 & 11,80 & 2,50 \\
\hline \multirow{2}{*}{ Programas Sociais } & $\mathrm{N}$ & 3 & 2 & 5 \\
\hline & $\%$ & 1,20 & 5,90 & 1,80 \\
\hline \multirow{2}{*}{ Geração de Energia } & $\mathrm{N}$ & 3 & 1 & 4 \\
\hline & $\%$ & 1,20 & 2,90 & 1,40 \\
\hline \multirow{2}{*}{ Outros } & $\mathrm{N}$ & 10 & 1 & 11 \\
\hline & $\%$ & 4,10 & 2,90 & 4,00 \\
\hline \multirow{2}{*}{ Total } & $\mathrm{N}$ & 244 & 34 & 278 \\
\hline & $\%$ & 100 & 100 & 100 \\
\hline
\end{tabular}

Fonte: Elaboração própria.

A diferença entre o Congresso e a Corte de Contas é mais acentuada quando observamos as suas iniciativas de auditoria pela clivagem entre temas sociais e econômicos. A fiscalização do Tribunal concentra-se na regulação econômica com $91,4 \%$, enquanto entre as auditorias solicitadas pelo Congresso este percentual cai para $61,8 \%$. É importante destacar que esta distinção entre regulação econômica e social é muito tênue e que a maior parte das ações regulatórias envolve ambas as áreas. 
DOSSIÊ GOVERNABILIDADE, INFORMAÇÃO E FISCALIZAÇÃO POLÍTICA

Tabela 5 - Tipo de Regulação por Ator que Iniciou a Auditoria

\begin{tabular}{c|c|c|c|c}
\hline \multirow{2}{*}{$\begin{array}{c}\text { Ator que Iniciou a } \\
\text { Auditoria }\end{array}$} & & \multicolumn{3}{|c}{ Tipo de Regulação } \\
\cline { 3 - 5 } & & Econômica & Social & Total \\
\hline \multirow{2}{*}{ TCU } & $\mathrm{N}$ & 223 & 21 & 244 \\
\hline \multirow{2}{*}{ Congresso Nacional } & $\%$ & 91,4 & 8,6 & 100 \\
\hline \multirow{2}{*}{ Total } & $\mathrm{N}$ & 21 & 13 & 34 \\
\cline { 2 - 5 } & $\%$ & 61,8 & 38,2 & 100 \\
\cline { 2 - 5 } & $\%$ & 244 & 34 & 278 \\
\hline
\end{tabular}

Fonte: Elaboração própria.

Esta ampla atuação do TCU na fiscalização das agências reguladoras tem apresentado resultados positivos para a transparência do processo decisório na arena regulatória. Menezes (2010) ao realizar uma análise de discurso das auditorias realizadas pelo TCU sobre as agências mostra que o controle externo tem encontrado irregularidades realizadas pelas instituições regulatórias e determinado mudanças importantes que alteram a direção da política pública.

Apenas como exemplo ilustrativo o acórdão 1.778 de 2004 apresenta a decisão do TCU sobre a metodologia utilizada pela Anatel para fiscalizar a universalização de Telefones de Uso Público (TUP) no interior do país. Nesta auditoria, segundo o TCU, a agência reguladora não possuía um cadastro das localidades em que deveriam ser instalados os TUP's, de modo que as concessionárias deveriam informar em um sistema nacional os locais. $O$ resultado foi que todas as concessionárias tinham incentivos para relatar localidades dentro da área de concessão das demais e nunca dentro da sua área. É importante ressaltar que os TUP's em áreas isoladas são muito caros e poucos rentáveis para as empresas do setor. Ao término da fiscalização o Tribunal determinou que a agência reformulasse sua metodologia para definição de localidade e o processo de fiscalização que também apresentava problemas. A princípio a agência reguladora contestou a decisão, mas acabou reformulando sua metodologia. Esta decisão beneficiou as populações rurais e indígenas do interior do país que dependem destes telefones para se comunicarem.

Os congressistas salientam que, como órgão auxiliar do Poder Legislativo, o TCU tem um papel importante de alertar sobre irregularidades nas agências reguladoras.

[...] Eu tenho uma opinião assim, tudo o que utiliza recurso público, deve estar obrigatoriamente submetido à fiscalização do órgão público que é o Tribunal de Contas da União, então quero dizer que como as agências reguladoras recebem recurso público para executar, elas devem estar submetidas sim a auditoria (sic) (Senadora). 
[...] O TCU é absoluto. O Tribunal de Contas da União é um instrumento da União, de fiscalização, que tem que permanecer existindo. As agências reguladoras são órgãos de atuação, de normatização, que tem que se sujeitar, evidentemente, à fiscalização e auditoria do TCU (sic) (Senador).

Eu acompanho! Até porque, como Presidente, eu recebo aqui todas as auditorias que são feitas nas agências que são vinculadas à Comissão [...] (sic) (Deputado Federal, Presidente de Comissão).

Os resultados iniciais apresentados neste artigo mostram que o TCU funciona para o Congresso como um mecanismo de monitoramento do parlamento sobre as agências, fornecendo informações sobre as auditorias realizadas, sejam elas solicitadas pelos Congressistas ou de iniciativa da própria Corte de Contas. Por outro lado, as auditorias do Tribunal também podem fornecer subsídios técnicos para o controle do tipo alarme de incêndio. Primeiro, porque os temas auditados são selecionados pelos auditores sem um critério formal que possibilite uma previsibilidade por parte do ente regulador. Segundo, algumas das auditorias de fiscalização sobre as agências apresentam certo destaque na mídia, podendo ser utilizadas como instrumento de pressão sobre os políticos eleitos, parlamentares ou o Executivo, para se posicionarem acerca de alguma medida regulatória emitida pelo ente autônomo.

\section{Considerações finais}

Os resultados da pesquisa mostram uma ampla atuação do TCU na fiscalização sobre as agências reguladoras. Como descrito na seção anterior a Corte de Contas tem realizado auditorias em diversas áreas, verificando o conteúdo das decisões na arena regulatória. Sendo a maioria delas de iniciativa do Tribunal.

Retornando ao argumento inicial de delegação de poderes: até que ponto a fiscalização operacional do Tribunal de Contas da União atende aos interesses do Congresso Nacional?

As mudanças políticas e sociais ocorridas nos últimos anos no Estado brasileiro, com a liberalização econômica e as privatizações, apresentaram como consequência o aumento da complexidade das arenas regulatórias. Empresas privadas passaram a prover serviços antes administrados pelo Estado, ao mesmo tempo, em que os direitos dos usuários-cidadãos foram expandidos pela Constituição de 1988. Todo este arranjo evidencia a necessidade de instituições que possibilitem a realização de controles horizontais e verticais que garantam um processo decisório transparente. 
Neste ponto, o papel desempenhado pelo Tribunal de Contas da União na fiscalização sobre as atividades fins das agências reguladoras tem se mostrado de fundamental importância. A quantidade e o conteúdo das auditorias realizadas pela Corte de Contas demonstram a atuação do órgão no controle externo horizontal dos entes regulatórios.

Do ponto de vista do Congresso brasileiro, a fiscalização e o monitoramento das recomendações dessas ações por parte do Tribunal de Contas liberam os parlamentares para as atividades legislativas, em detrimento de um amplo papel investigativo. A grande concentração do TCU em temas da regulação econômica é compensada, em alguma medida, pela iniciativa de alguns parlamentares que demandam auditorias de temas sociais.

Considero que um dos principais efeitos da atuação do TCU é na redução do excesso de discricionariedade do ente regulador, tornando o regime regulatório mais transparente e com melhor equilíbrio de interesses. A transparência é a primeira garantia de controle do ente autônomo. Ela permite que a sociedade civil, os concessionários e os usuários recorram contra a excessiva discricionariedade do regulador autônomo, garantindo, assim, a estabilidade do regime regulatório.

Por fim, a mudança institucional no arcabouço regulatório resultou em um efeito não esperado pelos reformistas da década de 1990, a saber: um aumento da presença do Legislativo na fiscalização das políticas públicas no Brasil. Se, antes da reforma, os setores regulados pelas agências reguladoras eram controlados pelas burocracias do Executivo, a partir das privatizações e da delegação de poderes às agências reguladoras, o Legislativo, através do TCU, passou a fiscalizar de forma mais intensa a implementação das políticas destes setores, embora o Executivo continue com uma atuação forte, através dos Ministérios de cada setor.

Monique Menezes é Cientista Social pela Universidade Federal Fluminense (UFF), Mestre e Doutora em Ciência Política pelo Instituto Universitário de Pesquisa do Rio de Janeiro (IUPERJ). Atualmente é bolsista do Instituto de Pesquisa Econômica e Aplicada (IPEA/DF) e Professora do Mestrado em Ciência Política da Universidade Federal do Piauí (UFPI).

E-mail: moniquemenezes@ufpi.edu.br

\section{Referências}

BOSCHI, Renato; LIMA, Maria Regina. O Executivo e a Construção do Estado no Brasil: Do Desmonte da Era Vargas ao Novo Intervencionismo Regulatório. In: VIANNA, Luiz Werneck (Org.). A Democracia e os Três Poderes no Brasil. Belo Horizonte/Rio de Janeiro: Editora UFMG/IUPERJ/FAPERJ, 2002. p. 195253. 
BOURN, John. O papel do grupo de trabalho de privatização da INTOSAI e a responsabilização dos entes reguladores no Reino Unido. Revista do TCU, Brasília, ano 36, n. 104, p. 17-22, abr.-jun. 2005.

DINIZ, Eli. Uma perspectiva analítica para a Reforma do Estado. Lua Nova Revista de Cultura e Política, São Paulo, n. 45, p. 29-48, 1998.

FERREIRA, Aurélio Buarque de Holanda. Mandante. In: . Novo Dicionário Aurélio da Língua Portuguesa. FERREIRA, Mariana; ANJOS, Margarida (Coords.). Curitiba: Positivo, 2009. p. 1262.

FISCHER, Louis. The Politics of Shared Power: congress and the executive. Washington: Congressional Quartely Press, 1981.

GILARDI, Fabrizio. Delegation in the Regulatory State: Independent Regulatory Agencies in Western Europe. Cheltenham/UK; Northampton, MA/USA: Edward Elgar, 2008.

KIEWIET, Roderick; MCCUBBINS, Mathew. The Logic of Delegation: congressional parities and the appropriation process. Chicago: The University of Chicago Press, 1991.

LODGE, Martin. Accountability and Transparency in Regulation: critiques, doctrines and instruments. In: JORDANA, Jacint; LEVI-FAUR, David (Orgs.). The Politics of Regulation: institutions and regulatory reforms for the age of governance. Cheltenham, UK; Northampton, MA/USA: Edward Elgar, 2004. p. 124-144.

LOWI, Theodore. The End of Liberalism: The Second Republic of the United States. New York: Norton, 1979.

LUPIA, Arthur; MCCUBBINS, Mathew. The Democratic Dilemma: can citizens learn what the need to know? Cambridge: Cambridge University Press, 1998.

MAJONE, Giandomenico. Do Estado Positivo ao Estado Regulador: causas e consequências de mudanças no modo de governance. Revista do Serviço Público - RSP, Brasília, ano 50, n. 1, p. 5-36, jan.-mar. 1999.

. The Credibility Crisis of Community Regulation. Journal of Common Market Studies, Oxford/Malden, v. 38, n. 2, p. 273-302, jun. 2000. 
MCCUBBINS, Mathew; SCHWARTZ, Thomas. Congressional oversight overlooked: police patrols versus fire alarms. American Journal of Political Science, Bloomington, v. 28, n. 1, p. 165-179, feb. 1984.

MELO, Marcus André. A Política Regulatória: Responsabilização, Credibilidade e Delegação. Revista Brasileira de Ciências Sociais, São Paulo, v. 16, n. 46, p. 56-68, jun. 2001.

MENEZES, Monique. Autonomia e Controle das Agências Reguladoras: o papel do Tribunal de Contas da União no arranjo regulatório brasileiro. 2010. $256 \mathrm{f}$. Tese (Doutorado em Ciência Política) - Programa de Pós-Graduação em Ciência Política, Instituto Universitário de Pesquisas do Rio de Janeiro, Rio de Janeiro, 2010.

MOE, Terry. The New Economics of Organization. American Journal of Political Science, Bloomington, v. 28, n. 4, p. 739-777, nov. 1984.

MORENO, Erika; CRISP, Brian; SHUGART, Mathew. The Accountability Deficit in Latin America. In: MAINWARING, Scott; WELNA, Christopher (Orgs.). Democratic Accountability in Latin America. Oxford: Oxford University Press, 2003. p. 79-131.

O'DONNELL, Guilhermo. Delegative Democracy. Journal of Democracy, Washington, v. 5, n. 1, p. 55-69, jan. 1994.

PÓ, Marcus Vinicius; ABRUCIO, Fernando. Desenho e Funcionamento de Mecanismos de Controle e Accountability das Agências Reguladoras Brasileiras: semelhanças e diferenças. Revista de Administração Pública RAP, Rio de Janeiro, v. 40, n. 4, p. 679-698, jul.-ago. 2006.

PRZEWORSKI, Adam. States and Markets: a primer in political economy. Cambridge: Cambridge University Press, 2003.

SALGADO, Lúcia Helena. Agencia Regulatória na Experiência Brasileira: um panorama do atual desenho institucional. Rio de Janeiro: Ipea, 2003. (Texto para Discussão n. 941).

SCOTT, Collin. Accountability in the Regulatory State. Journal of Law and Society, Oxford, v. 27, n. 1, p. 38-60, mar. 2000.

THATCHER, Mark; STONE SWEET, Alec. Theory and Practice of Delegation to Non-Majoritarian Institutions. In: (Orgs.). The Politics of Delegation. London: Frank Cass, 2003. p. 1-22. 
DOSSIÊ GOVERNABILIDADE, INFORMAÇÃO E FISCALIZAÇÃO POLÍTICA

WEINGAST, Barry. Caught in the Middle: the president, congress, and the political-bureaucratic system. In: ABERBACH, Joel; PETERSON, Mark (Orgs.). Institution of American Democracy: executive branch. Oxford: Oxford University Press, 2006. p. 312-343.

WILKS, Stephen; BARTLE, Ian. The Unanticipated Consequences of Creating Independent Competition Agencies. West European Politics, Londres, v. 25, n. 1, p. 148-172, jan. 2002.

Texto recebido em 16/08/2012.

Aprovado em 29/10/2012. 